\title{
Using Parasitic Load to Measure the Effect of Anthropogenic Disturbance on Vervet Monkeys
}

\author{
Harriet R. Thatcher(10, ${ }^{1,2}$ Colleen T. Downs, ${ }^{2}$ and Nicola F. Koyama ${ }^{1}$ \\ ${ }^{1}$ School of Natural Sciences and Psychology, Liverpool John Moores University, Byrom St, Liverpool L3 3AF, UK \\ ${ }^{2}$ School of Life Sciences, University of KwaZulu-Natal, Pietermaritzburg Campus, KwaZulu-Natal, South Africa
}

\begin{abstract}
Vervet monkeys, Chlorocebus pygerythrus, thrive in urban areas of KwaZulu-Natal, South Africa, and present a suitable model to assess parasitic load as a measure of anthropogenic disturbance, such as urbanization. We collected vervet monkey faecal samples from four study sites representing a gradient of land use and urbanization. We assessed faecal parasites using the faecal flotation method calculating eggs per gram and parasite richness. Overall, the more urban vervet monkey populations had a significantly higher parasite richness and abundance. Our study shows the applicability of using parasite load to measure the effect of urbanization on wildlife.
\end{abstract}

Keywords: Zoonosis, Transmission, Human-wildlife, Land-use gradient, Management

Dramatic increases in human populations have resulted in drastic changes to the function and biodiversity of the natural ecosystem (Sauvajot 1998; Bonier et al. 2006). Though effects are species specific, certain wildlife species have been able to adapt to ecological changes and thrive in these conditions (McLennan et al. 2017). However, the stresses of an expanding anthropogenic environment can have negative consequences for wildlife such as poor body condition and increased parasite load (Borg et al. 2015; Soto-Calderón et al. 2016). Understanding the effects of anthropogenic disturbance, such as urbanization, on hostparasite relationships and zoonotic transmission has implications not only for the health of humans and their livestock, but also for wildlife conservation and biodiversity (Soulsbury and White 2015; Humle and Hill 2016; Cable et al. 2017).

Published online: August 8, 2018

Correspondence to: Harriet R. Thatcher, e-mail: h.thatcher@2010.ljmu.ac.uk
Urbanization varies dramatically from large cities to small settlements, and therefore, the effects are difficult to quantitatively measure (Niemelä and Kotze 2009; Bennett and Gratton 2012; Mackenstedt et al. 2015). Urbanization creates unique habitats through a process of increasing human populations and anthropogenic structures (Werner 2011). With the continuing encroachment of anthropogenic pressures, most wildlife studies include some level of human disturbance in their data (e.g. McLennan et al. 2017). However, with the exception of Lane et al.'s (2011) study on Macaca fascicularis, few primate studies include highly human-populated urban areas. Furthermore, the majority of anthropogenic parasite studies focus on comparisons between only two study sites. However, the results of these studies show varying effects of increasing urbanization on zoonotic transmission and parasite infection rates (Cable et al. 2017). Creating a quantitative measure for urban influences is complex, but currently a gradient scale from rural to urban is the most commonly 
acknowledged method (Bradley and Altizer 2006; Shochat et al. 2007; Bennett and Gratton 2012).

Vervet monkeys, Chlorocebus pygerythrus, are a common generalist primate that has become highly populated within urban areas of KwaZulu-Natal, South Africa (Patterson et al. 2016; 2017; 2018). They are, therefore, a suitable model to investigate anthropogenic influences on wildlife parasite load. Furthermore, they are frequent raiders of anthropogenic food sources increasing opportunities for zoonotic transmission (Eley 1989; Hahn et al. 2003; Hegglin et al. 2015). Research into anthropogenic influences on parasite load in vervet monkeys is limited to two studies (Gaetano et al. 2014; Valenta et al. 2017). Gaetano et al.'s (2014) research suggests that ecological factors are better predictors of parasitism concentrations than anthropogenic contact. However, the applicability of their findings is limited by both small sample size and relatively short time span. Valenta et al. (2017) reported a higher parasite richness in vervet monkeys in an anthropogenic disturbed habitat compared with historical data in less disturbed vervet monkey populations. However, they were unable to interpret their results clearly due to variation in sample sizes and methods across historical studies. Finally, the habitats assessed in both studies had low anthropogenic stress, highlighting a need to assess a wider range of anthropogenic influences on vervet monkeys.

We aimed to establish whether a relatively low-cost methodological approach to assessing parasite load could reflect an urbanization gradient. We used four sites throughout KwaZulu-Natal, South Africa. We chose study sites to reflect anthropogenic influences along a ruralperiurban-urban gradient (Table 1), including the previously neglected category of a highly human-populated urban area. Vervet monkey troop size information was collected using standard point count protocol (Hutto et al. 1986). We obtained human populations and anthropogenic structure numbers from site officials and governmental records (STATS SA, 2017) (Table 1).

We collected vervet monkey faecal samples over 6 months from October 2016-March 2017. We collected 286 specimens immediately after defecation following standard sampling techniques, storing them in $70 \%$ ethanol (Gillespie 2006).

Vervet monkey samples were prepared for analyses using the faecal flotation method (Gillespie 2006). We pipetted the prepared sample from the centre of the tube into chambers of a McMaster slide. The slide was assessed using standard methods (Cringoli et al. 2004). We used an electron phase microscope to scan the slide using a $\AA \sim 10$ objective lens and identified parasite eggs based on morphology. Digital photographs were taken of any vervet monkey parasites observed.

We converted raw data from the McMaster analysis to eggs per gram (Dunn and Keymer 1986) and compiled information on parasite richness per sample. We classed vervet monkeys as infected if their faecal sample had one or more parasite(s) and present the percentage of samples infected.

Table 1. Information on Vervet Monkey Faecal Parasite Samples Collected from Four Sites Representing a Rural-Periurban-Urban Gradient in KwaZulu-Natal, South Africa.

\begin{tabular}{|c|c|c|c|c|c|}
\hline Site & $\begin{array}{l}\text { Human density per } \\
\mathrm{km}^{2}\end{array}$ & $\begin{array}{l}\text { Anthropogenic structure per } \\
\mathrm{km}^{2}\end{array}$ & $\begin{array}{c}\text { Group } \\
\text { size }\end{array}$ & $\begin{array}{l}\text { Mean no. samples }( \pm S D) \text { per } \\
\text { month }\end{array}$ & $\begin{array}{l}\text { McKinney classifi- } \\
\text { cation }\end{array}$ \\
\hline $\begin{array}{l}\text { Private re- } \\
\text { serve }\end{array}$ & 2 & 2 & $\begin{array}{l}20 \\
49 \\
16\end{array}$ & $\begin{array}{l}49(9 \pm 0.7) \\
27(4.5 \pm 1.21) \\
31(5 \pm 0.3)\end{array}$ & CDEB \\
\hline $\begin{array}{l}\text { Industrial } \\
\text { land }\end{array}$ & 48 & 4 & 22 & $28(4 \pm 0.3)$ & DDIC \\
\hline Gated estate & 2970 & 275 & $\begin{array}{l}12 \\
23 \\
27 \\
42\end{array}$ & $\begin{array}{l}24(4 \pm 0.2) \\
23(4 \pm 0.3) \\
27(5 \pm 0.3) \\
31(5 \pm 0.3)\end{array}$ & $\mathrm{HG}_{3} \mathrm{LC}$ \\
\hline City centre & 3100 & 352 & $\begin{array}{l}28 \\
35\end{array}$ & $\begin{array}{l}22(4 \pm 0.2) \\
24(4 \pm 0.4)\end{array}$ & HKPO \\
\hline
\end{tabular}


We analysed data using R v3.3.2 (R Project 2017). Data for both eggs per gram and parasite richness were not normally distributed (Shapiro-Wilks test, $p \leq 0.001$ ) (Ghasemi and Zahediasl 2012). We ran two generalized linear models, with eggs per gram and parasite richness as separate dependent variables. We tested eggs per gram with a Poisson distribution and log link suitable for frequency data and species richness with a gamma distribution and log link for non-normal data. For both models, to avoid collinearity, we combined human density per $\mathrm{km}^{2}$ and anthropogenic structure per $\mathrm{km}^{2}$ to create a fixed effect. We also included vervet monkey troop size as a fixed effect. Generalized linear models were specified using the lme4 package (Bates 2010). To test whether the fixed effects explained variation we used a likelihood ratio test ('anova' command set to 'Chisq') to compare the maximum model against the null model (Zuur et al. 2009). Furthermore, we bootstrapped our confidence intervals to account for uneven sampling within our data set (Davison and Hinkley 1997).

Overall, $58 \%$ of the 286 vervet monkey samples had some level of parasitic infection. Parasites identified were Coccidia sp., Strongyloides sp., Tricuris sp., Ascaris sp. and Oesophagostomum sp. Eggs per gram were significantly higher in vervet monkeys from more urbanized sites (Table 2, Fig. 1a). Increasing vervet monkey troop size also had a significant positive effect on eggs per gram (Table 2, Fig. 1b). Parasite richness was significantly higher in vervet monkeys inhabiting more urbanized habitats (Table 3, Fig. 2a). Increasing troop size also had a significant positive effect on vervet monkeys' parasite richness (Table 3, Fig. 2b).

Parasite eggs per gram and species richness were significantly higher in vervet monkeys living in areas of higher human density and greater anthropogenic structure than in lower human density and anthropogenic structure, sup- porting previous studies (e.g. Valenta et al. 2017). As expected, vervet monkey troop size was a significant predictor across sites for both eggs per gram and parasite richness.
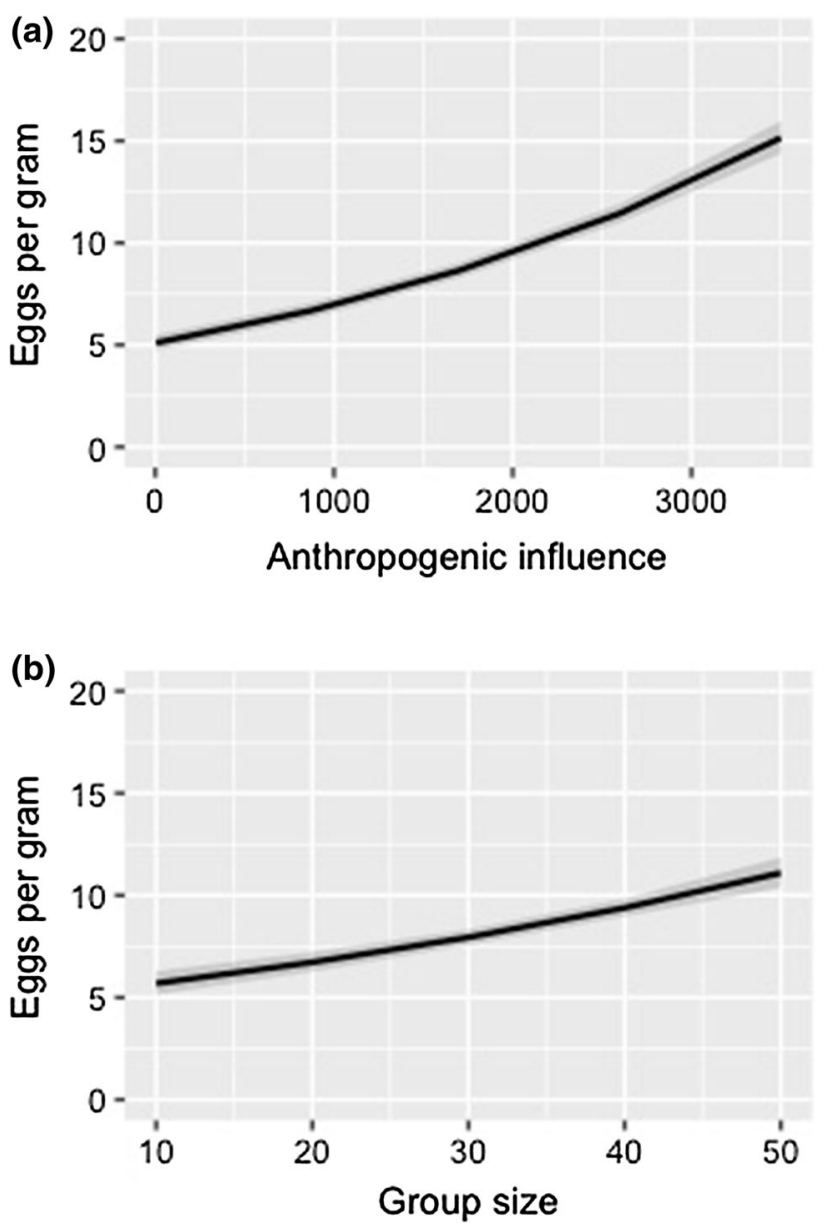

Fig. 1. Eggs per gram obtained from vervet monkey faecal samples collected from four sites representing a gradient of urbanization in KwaZulu-Natal, South Africa, where a shows the positive significant effect of increased anthropogenic influence on eggs per gram of vervet monkeys ( $p \leq 0.001$ ), and $\mathbf{b}$ shows the positive significant effect of troop size on eggs per gram of vervet monkeys ( $p=0.001$ ).

Table 2. Maximum Model Output from Likelihood Ratio Test on the Eggs per gram of Vervet Monkey Faecal Samples $(n=286)$ Collected Along a Rural-Periurban-Urban Gradient in KwaZulu-Natal, South Africa.

\begin{tabular}{llllllll}
\hline Dependent variables & Fixed effects & Estimate & Standard error & Bootstrapped confidence intervals & Likelihood ratio test \\
& & & & Lower & Upper & Deviance & $p$ (chi) \\
\hline \multirow{2}{*}{ Eggs per gram } & Intercept & 1.45 & 1.64 & & & & \\
& Anthropogenic value km $\mathrm{km}^{2}$ & 2.84 & 4.51 & 0.02 & 0.01 & 35.83 & $\leq 0.001$ \\
& Troop size & 6.34 & 1.93 & 0.12 & 0.21 & 11.17 & 0.001 \\
\hline
\end{tabular}


Table 3. Maximum Model Output from Likelihood Ratio Test on the Parasite Richness in Vervet Monkey Faecal Samples $(n=286)$ Collected Along a Rural-Periurban-Urban Gradient in KwaZulu-Natal, South Africa.

\begin{tabular}{|c|c|c|c|c|c|c|c|}
\hline \multirow[t]{2}{*}{ Dependent variable } & \multirow[t]{2}{*}{ Fixed effects } & \multirow[t]{2}{*}{ Estimate } & \multirow[t]{2}{*}{ Standard error } & \multicolumn{2}{|c|}{ Bootstrapped confidence intervals } & \multicolumn{2}{|c|}{ Likelihood ratio test } \\
\hline & & & & Lower & Upper & Deviance & $p($ chi $)$ \\
\hline \multirow[t]{3}{*}{ Species richness } & Intercept & -8.87 & 2.39 & & & & \\
\hline & Anthropogenic value $\mathrm{km}^{2}$ & 2.47 & 4.34 & 0.01 & 0.03 & 29.96 & $\leq 0.001$ \\
\hline & Troop size & 1.23 & 5.38 & 0.01 & 0.02 & 5.27 & 0.021 \\
\hline
\end{tabular}
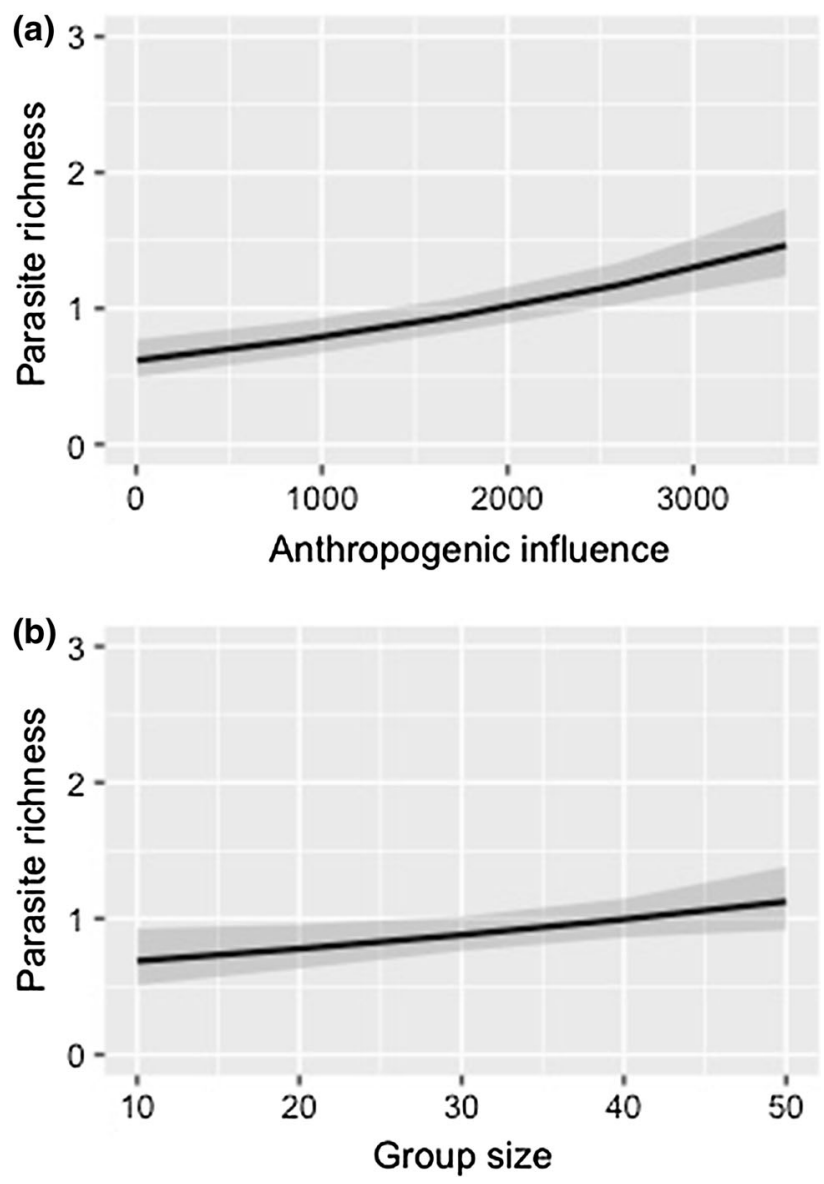

Fig. 2. Parasite richness obtained from vervet monkey faecal samples collected from four sites representing a gradient of urbanization in KwaZulu-Natal, South Africa where a shows the positive significant effect of increased anthropogenic influence on parasite richness of vervet monkeys ( $p \leq 0.001)$, and $\mathbf{b}$ shows the positive significant effect of troop size on parasite richness of vervet monkeys $(p=0.021)$.

Overall, our findings suggest that increased urbanization increases parasite load in vervet monkeys. Past results into the effects of anthropogenic disturbance on primate para- site load are mixed (Cable et al. 2017), although the majority of studies have compared only disturbed and undisturbed categories (Gillespie and Chapman 2008). Here, we analysed a gradient of urbanization, crucially including a highly human-populated urban area.

Anthropogenic pressures in dense urban environments, such as city centres, can have a negative impact both at an individual level (body condition: Eley 1989; Scheun et al. 2015) and at a group level (group stability: Sinha and Mukhopadhyay 2013). Supporting this, we found that parasite eggs per gram and richness were greater where anthropogenic pressures were higher. Increased anthropogenic influences result in increased contact with humans for wildlife that can facilitate disease transmission (Eley 1989; Hahn et al. 2003; Hegglin et al. 2015). A greater public awareness of the need to minimize food raiding opportunities for vervet monkeys could limit contact and reduce exposure to potential pathogens for both species. This is especially important considering the nature of foods raided. Both provisioned and raided foods generally contain a greater starch content which can contribute to increased parasite concentrations in host species (Weyher et al. 2006; Becker et al. 2015).

Although the vervet monkey parasite species found in our study were consistent with those found in other studies on urban primates, without genetic analysis we were unable to look at the direct transmission effects of these parasites, particularly as those we found are species specific. A greater understanding of zoonotic transmission would be a valuable asset, both from the perspective of human well-being and ecological biodiversity conservation (Díaz et al. 2006). Our findings highlight the suitability of the faecal flotation protocol as a relatively low-cost sampling method to monitor host-parasite responses to urbanization in species such as vervet monkeys. Such methodology could be included in urban management plans on a wider scale to 
assess the relationship between anthropogenic ecological change and wildlife health.

Our study is the first to provide baseline parasite data on vervet monkeys living in relatively highly urbanized areas. The wide range of sites used allowed us to conduct a controlled comparison of the effect of anthropogenic influences across a rural-periurban-urban gradient. Results highlight that increased urbanization is related to both increased eggs per gram and parasite richness in vervet monkeys. The study provides an important foundation for these successful urbanites. As urbanization increases, a greater understanding of urban exploiters' adaptations to ecological changes is important.

The datasets generated during the current study are available from the corresponding author on reasonable request.

\section{ACKNOWLEDGEMENTS}

We would like to thank K. Pillay, V. Hugo, Simbithi Ecoestate, Environmental Planning and Climate Protection Department, eThekwini Municipality, and Monkey Helpline for their assistance in collecting vervet monkey faecal samples. This research was financially supported by a Liverpool John Moores University PhD Scholarship, an Erasmus Mundus AESOP (A European and South African Partnership on Heritage and Past) grant (ES15DM0025), and the National Research Foundation (ZA). Ethical clearance was obtained from Liverpool John Moores University under permit number NK_HT/2017-6.

\section{Open Access}

This article is distributed under the terms of the Creative Commons Attribution 4.0 International License (http://c reativecommons.org/licenses/by/4.0/), which permits unrestricted use, distribution, and reproduction in any medium, provided you give appropriate credit to the original author(s) and the source, provide a link to the Creative Commons license, and indicate if changes were made.

\section{REFERENCES}

Bates DM (2010) lme4: Mixed-effects modeling with R, New York: Springer
Bennett AB, Gratton C (2012) Local and landscape scale variables impact parasitoid assemblages across an urbanization gradient. Landscape and Urban Planning 104:26-33

Becker DJ, Streicker DG, Altizer S (2015) Linking anthropogenic resources to wildlife-pathogen dynamics: a review and meta analysis. Ecology Letters 18:483-495

Bonier F, Martin PR, Sheldon KS, Jensen JP, Foltz SL, Wingfield JC (2006) Sex-specific consequences of life in the city. Behavioral Ecology 18:121-129

Borg C, Majolo B, Qarro M, Semple S (2015) A comparison of body size, coat condition and endoparasite diversity of wild barbary macaques exposed to different levels of tourism. Anthrozoös 27:49-63

Bradley CA, Altizer S (2006) Urbanization and the ecology of wildlife diseases. Trends in Ecology \& Evolution 22:95-102

Cable J, Barber I, Boag B, Ellison AR, Morgan ER, Murray K, et al. (2017) Global change, parasite transmission and disease control: lessons from ecology. Philosophical Transactions Royal Society B 372:20160088

Cringoli G, Rinaldi L, Veneziano V, Capelli G, Scala A (2004) The influence of flotation solution, sample dilution and the choice of McMaster slide area (volume) on the reliability of the McMaster technique in estimating the faecal egg counts of gastrointestinal strongyles and Dicrocoelium dendriticum in sheep. Veterinary Parasitology 123:121-131

Davison AC, Hinkley DV (1997) Bootstrap Methods and Their Application, Cambridge: University Press

Díaz S, Fargione J, Iii FSC, Tilman D (2006) Biodiversity loss threatens human well-being. PLoS Biology 4:1300-1305

Dunn A, Keymer A (1986) Factors affecting the reliability of the McMaster technique. Journal of Helminthology 60:260-262

Eley R (1989) Nutrition, body condition, activity patterns, and parasitism of free- ranging troops of olive baboons (Papio anubis) in Kenya. American Journal of Primatology 18:209-219

Gaetano TJ, Danzy J, Mtshali MS, Theron N, Schmitt CA, Grobler JP, Freimer N, Turner TR (2014) Mapping correlates of parasitism in wild South African vervet monkeys (Chlorocebus aethiops). South African Journal of Wildlife Research 44:56-70

Ghasemi A, Zahediasl S (2012) Normality tests for statistical analysis: a guide for non-statisticians. International Journal of Endocrinology and Metabolism 10:486-489

Gillespie TR (2006) Noninvasive assessment of gastrointestinal parasite infections in free-ranging primates. International Journal of Primatology 27:1129-1143

Gillespie TR, Chapman CA (2008) Forest fragmentation, the decline of an endangered primate, and changes in host-parasite interactions relative to an unfragmented forest. American Journal of Primatology 70:222-230

Hahn NE, Proulx D, Muruthi PM, Albert S, Altmann J (2003) Gastrointestinal parasites in free-ranging Kenyan baboons (Papio cynocephalus and P. anubis). International Journal of Primatology 24:271-279

Hegglin D, Bontadina F, Deplazes P (2015) Human-wildlife interactions and zoonotic transmission of Echinococcus multilocularis. Trends in Parasitology 31:167-173

Humle T, Hill C (2016) People-primate interactions: Implications for primate conservation. In: An introduction to primate conservation, Wich SA, Marshall AJ (editors), Oxford: Oxford University Press, pp 219-240 
Hutto RL, Pletschet SM, Hendricks P (1986) A fixed-radius point count method for nonbreeding and breeding season use. Auk 103:593-602

Lane KE, Holley C, Hollocher H, Fuentes A (2011) The anthropogenic environment lessens the intensity and prevalence of gastrointestinal parasites in Balinese long-tailed macaques (Macaca fascicularis). Primates 52:117-128

Mackenstedt U, Jenkins D, Romig T (2015) The role of wildlife in the transmission of parasitic zoonoses in peri-urban and urban areas International Journal for Parasitology: Parasites and Wildlife 4:71-79

McKinney $\mathrm{T}$ (2015) A classification system for describing anthropogenic influence on nonhuman primate populations. American Journal of Primatology 77:715-726

McLennan MR, Spagnoletti N, Hockings KJ (2017) The implications of primate behavioral flexibility for sustainable human primate coexistence in anthropogenic habitats. International Journal of Primatology 38:105-121

Niemelä J, Kotze DJ (2009) Landscape and urban planning carabid beetle assemblages along urban to rural gradients: A review. Landscape and Urban Planning 92:65-71

Patterson L, Kalle R, Downs CT (2016) Predation of artificial bird nests in suburban gardens of KwaZulu-Natal, South Africa. Urban Ecosystems 19:615-630

Patterson L, Kalle R, Downs CT (2017) A citizen science survey: perceptions and attitudes of urban residents towards vervet monkeys. Urban Ecosystems 20:617-628

Patterson L, Kalle R, Downs CT (2018) Factors affecting presence of vervet monkey troops in a suburban matrix in KwaZuluNatal, South Africa. Landscape Urban Plan 16:220-228

R Project (2017) The R Project for Statistical Computing. https:// www.r-project.org/. Accessed 11 November 2017

Sauvajot RM (1998) Patterns of human disturbance and response by small mammals and birds in chaparral near urban development. Urban Ecosystems 2:279-297
Scheun J, Bennett NC, Ganswindt A, Nowack J (2015) The hustle and bustle of city life: monitoring the effects of urbanisation in the African lesser bushbaby. Science of Nature 102:57

Shochat E, Warren PS, Faeth SH, Mcintyre NE, Hope D (2007) From patterns to emerging processes in mechanistic urban ecology. Trends in Ecology \& Evolution 21:186-191

Sinha A, Mukhopadhyay K (2013) The monkey in the town's commons revisited: An anthropogenic history of the Indian bonnet macaque. In: Radhakrishna S, Huffman M, Sinha A (eds) The macaque connection. Developments in primatology: progress and prospects, vol 43, Springer, New York, pp 187-208

Soto-Calderón ID, Acevedo-Garcés YA, Hernández-Castro JÁC, García-Montoya GM (2016) Physiological and parasitological implications of living in a city: the case of the white-footed tamarin (Saguinus leucopus). American Journal of Primatology 78:1272-1281

Soulsbury CD, White PCL (2015) Human-wildlife interactions in urban areas: A review of conflicts, benefits and opportunities. Wildlife Research 42:541-553

STATS SA (2017). Statistics South Africa. http://www.statssa.gov. za/. Accessed 11 November 2017

Valenta K, Twinomugisha D, Godfey K, Liu C, Schoof VAM, Chapman CA (2017) Comparison of gastrointestinal parasite communities in vervet monkeys. Integrative Zoology 12:512-520

Werner P (2011) The ecology of urban areas and their functions for species diversity. Landscape and Ecological Engineering 7:231-240

Weyher AH, Ross C, Semple S (2006) Gastrointestinal parasites in crop raiding and wild foraging Papio anubis in Nigeria. International Journal of Primatology 27:1519

Zuur AF, Ieno EN, Walker NJ, Saveliev AA, Smith GM (2009) Mixed effects models and extensions in ecology, New York: Springer Science and Business Media 